Studia Rossica Gedanensia, 6/2019, 97-106, ISSN 2392-3644 (online), ISSN 2449-6715 (print) DOI: https://doi.org/10.26881/srg.2019.6.07

\title{
КАВКАЗ В СИСТЕМЕ ГЕОПОЛИТИЧЕСКИХ ПРЕДСТАВЛЕНИЙ Ф.М. ДОСТОЕВСКОГО ${ }^{1}$
}

\author{
МАРИЯ МИХНОВЕЦ \\ Санкт-Петербургское Государственное бюджетное учреждение культуры \\ «Литературно-мемориальный музей Ф. М. Достоевского» \\ ул. Достоевского д. 2/5, 191002, г. Санкт-Петербург, Россия \\ e-mail: mikhnovets@dostoevsky.spb.ru \\ ORCID: https://orcid.org/0000-0002-7818-2321 \\ (получено 30.08.2019; принято 5.10.2019)
}

\section{Abstract \\ The Geopolitics of the Caucasus in the Works of Fyodor Dostoevsky}

The paper explores the geopolitics of the Caucasus in Fyodor Dostoevsky's sociopolitical works. The writer clearly sees the Caucasus as being part of the Russian Empire and its most recent acquisition. An important feature of the region is its fundamental "otherness", however its nature and identity are not explored. The paper focuses in particular on the religious affiliation of the Caucasus, which Dostoevsky sees as homogeneous in its symbolic connection with the Muslim world.

Key words: Dostoevsky, A Writer's Diary, geopolitics, the Caucasus, worldview

\section{Резюме}

Статья посвящена вопросу о месте Кавказа в системе геополитических воззрений Ф.М. Достоевского. На материале публицистики писателя показано, что Кавказ в его картине мира является территорией, принадлежащей Российской империи и недавно вошедшей в ее состав. Характерной чертой региона оказывается его

1 Исследование выполнено при финансовой поддержке РФФИ в рамках научного проекта № 18-012-90020/18. 
принципиальная «инаковость», однако вопрос о ее специфике не проблематизируется. Особое место в статье посвящено вопросу о религиозной принадлежности Кавказа, который для Достоевского оказывается гомогенным в своей символической причастности к мусульманскому миру.

Ключевые слова: Достоевский, Дневник писателя, геополитика, Кавказ, картина мира

В русистике сформировался огромный корпус исследований, которые можно объединить общей широкой темой «русская литература и Кавказ». Начало ее научному осмыслению было положено еще в 40. годах XX в. советским литературоведом грузинского происхождения В.С. Шадури (Шадури 1948), и с тех пор различные аспекты художественных и публицистических произведений русских писателей изучались в свете самых разнообразных методологий (Layton 1994; Эйдельман 1990; Багратион-Мухранели 1994; Чхаидзе 2015; Иванеско 2018 и др.). Обусловлено такое количество работ в том числе самой спецификой отечественной литературной традиции: кавказская тема является едва ли не сквозной для всей русской словесности XIX века. Для русской литературы Кавказ является не менее важным топосом, чем Петербург, Москва или Крым. Точно также, как о петербургском или усадебном текстах русской литературы, можно говорить о кавказском тексте русской литературы.

Изучению кавказской темы в творчестве Ф.М. Достоевского посвящено лишь несколько работ. Отчасти это обусловлено тем, что при всей обширности географии перемещений и путешествий Достоевский не посещал Кавказ. Также кавказский регион не становился местом действия в художественных произведениях писателя, среди многочисленных героев творчества Достоевского только Аким Акимович и Алей из «Записок из мёртвого дома» связаны с Кавказом, и кавказский мотив имеет характеро- и сюжетообразующую функции. Компаративистскому анализу образов этих героев посвящена работа китайского исследователя Ми Сюйян (Сюйян 2017). Косвенно касается кавказской темы статья П.В. Алексеева, посвященная мусульманскому востоку в поэтике писателя (Алексеев 2013). Отечественный философ и литературовед В.К. Кантор несколько раз упоминает Кавказ в рамках изучения вопроса о культурно-философском национализме и т.н. «имперском кризисе» Дневника писателя (Кантор 2010: 256-258), но в цели работы не входит развернутое обращение к кавказской теме.

Исследование же представлений Ф.М. Достоевского о Кавказе в геополитическом аспекте предпринимается впервые, сама традиция изучения творчества писателя под этим углом зрения находится на начальной стадии формирования (Щербинин, Щербинина 2018). Изучение того, какими характеристиками наделяется Кавказ в публицистическом, эпистолярном и художественном наследии писателя, позволяет не только заполнить «белое пятно» на геополитической карте в картине мира Достоевского, но и внести существенные дополнения в систему представлений о специфике его мышления, особенностях понимания 
взаимоотношения Запада и Востока, славянского и западного, православного и мусульманского миров. Настоящее исследование выполнено в традициях методологии постколониальных исследований.

Ещё в 1854 году Кавказ в восприятии Достоевского являлся частью Российской империи. В этом году в письме брату Михаилу от 30 января - 22 февраля Достоевский рассказывает о возможных местах своей ссылки после сибирской каторги, и город Семипалатинск видится им как «почти киргизская степь» и в этом качестве противопоставляется «нашему» Кавказу, который для писателя «все-таки Россия» (Достоевский 1985: XXVIII (1): 172). Подобной точки зрения придерживается Достоевский и в 1870-х гг.: в набросках к Дневнику писателя за 1876 год появляется фраза: «Кавказцы - наши земли» (Достоевский 1981: XXIII: 305).

При этом Кавказ для него - своеобразная отметка «края мира», пограничная линия «своего» пространства. Так, например, в Записках из Мёртвого дома писатель размышляет о бегунах, которые всю жизнь проводят в скитаниях: «У нас в остроге мне указывали на одного из таких бегунов (...). Бывал он и на южной русской границе за Дунаем, и в киргизской степи, и в Восточной Сибири, и на Кавказе - везде побывал» (Достоевский 1972: IV: 174). Все перечисленные регионы на момент написания книги относительно недавно вошли в состав Российской империи, были фронтирами государства и поэтому появление в размышлениях пишущего такого ряда топонимов неслучайно.

В рамках этой же логики возникает ряд топонимов в Дневнике писателя за 1873 год в главе Влас. Достоевский, размышляя о феномене старчества предполагает, откуда могут прийти за советом: «Живет этот старец, положим, в Херсонской губернии, а к нему едут или даже идут пешком из Петербурга, из Архангельска, с Кавказа и из Сибири» (Достоевский 1980: XXI: 33). Достоевский выстраивает ряд «Петербург-Архангельск-Кавказ-Сибирь», все дальше перемещаясь от административного центра к периферии. Заметим, что подобное сближение Кавказа и Сибири впервые появляется еще в его рецензии Гаваньские чиновники в домашнем быту, или Галерная гавань во всякое время дня и года. Материал был опубликован в февральском номере журнала «Время» за 1861 год и традиционно приписывается Достоевскому. Писатель привлекает внимание к феномену читательской реакции на выход в свет любого нового произведения: начинается «муссированье нового громадного произведения, и до того взмыливают и до того муссируют, что это взмыливанье отзывается наконец и в Сибири, и на Кавказе, и даже в Остзейских провинциях, где, как известно, живут немцы, печатающие по-русски» (Достоевский 1984b: XXVII: 147). Остзейские провинции - территории современных стран Прибалтики, которые вошли в состав Российской империи в начале XVIII века после окончания Северной войны и которые обладали при этом существенной долей автономии. Перечисляя в одном ряду Кавказ, Сибирь и Прибалтику, Достоевский подчеркивает особый статус этих земель, акцентирует их «инаковость».

Подобная мысль повторяется и в Дневнике писателя за май 1876 года. В статье Областное новое слово Кавказ понимается как окраинный источник притока «новых сил», но представлен таким же «чужим», как и Рига: 
И не вся ли Россия, напротив, притекала и толпилась в Петербурге и Москве, во все полтораста лет сряду, и, в сущности, сама себя и вела, беспрерывно обновляясь свежим притоком новых сил из областей своих и окраин, в которых, мимоходом говоря, задачи были совсем одни и те же, как и у всех русских в Москве или Петербурге, в Риге или на Кавказе, или даже где бы то ни было (Достоевский 1981: XXIII: 6).

Таким образом, на протяжении ряда лет Достоевский неизменно объединяет Кавказ, Сибирь, «Остзейские провинции», «киргизские степи» (территории современного Казахстана) как земли, не являющиеся исконно русскими, населенные собственными этносами и лишь отчасти ассимилировавшимися. Эти регионы оказываются в роли своеобразного «своего иного» (Лекке, Чхаидзе 2018: 14): они, с одной стороны, включены в состав Российской империи, с другой стороны, осознаются русским писателем как инородные, «иные».

Подобное понимание места Кавказа в составе Российской империи прослеживается и в статье По поводу выставки из Дневника писателя за 1873 год. Достоевский рассуждает о современной ему пейзажной живописи и ее национальной специфике:

Я, конечно, не говорю, что в Европе не поймут наших, например, пейзажистов: виды Крыма, Кавказа, даже наших степей будут, конечно, и там любопытны. Но зато наш русский, по преимуществу национальный, пейзаж, то есть северной и средней полосы нашей Европейской России, я думаю, тоже не произведет в Вене большого эффекта (Достоевский 1980: XXI: 70).

Для Достоевского Крым, Кавказ, степи - безусловно «наши», то есть административно закреплены за территориями российского государства. Но исходя из контекста всего высказывания видно, что в картине мира писателя эти регионы не являются русскими, «нашими».

Такое понимание сопровождается у Достоевского рядом особенностей. Писатель не проблематизирует вопрос о коренном населении Кавказа, для него самобытного населения Кавказа будто бы и нет. Достоевский не задается вопросом о специфике его инаковости. В то же время в российском обществе проявлялась совершенно противоположная тенденция: выявить особенности определенного края. Так, например, в середине XIX века русское географическое общество было озабочено вопросом о необходимости исследования Кавказа. В 1860 году выходит большой труд Д.И. Романовского Кавказ и кавказская война (Романовский 1860). Знаменательно, что в журнале «Заря» в 1870 году печатался и рассказ Вечный муж Достоевского, и статья Русские люди на Кавказе А.И. Руновского - военного пристава при плененном Шамиле, опубликовавшего ранее записки о ходе Кавказской войны, о мюридизме, газаве и о самом имаме. И упомянутые нами выше, и другие работы описывали этнографические и конфессиональные особенности Кавказа, в них обращалось внимание на различие в ментальности кавказских народов. Достоевский же не проявляет интерес к природе кавказского края, не задается вопросами о различиях между многочисленными кавказскими этносами. 
При этом в публицистике у Достоевского последовательно проведен колониально-империалистический взгляд на Кавказ. Для него Кавказ - «младший брат» великоруса:

Вы тревожитесь, чтобы «старший брат в семье» (великорус) не оскорбил как-нибудь сердца младшего брата (татарина или кавказца) (...). Позвольте, что ж это такое? Русская земля принадлежит русским, одним русским, и есть земля русская, и ни клочка в ней нет татарской земли. Татары, бывшие мучители земли русской, на этой земле пришлецы (Достоевский 1981: XXIII: 127).

В этой логике получается, что великорус волен поступать с коренным населением Кавказа так, как ему угодно. Достоевский в Дневнике писателя за июльавгуст 1876 года в главе Выезд за гранииу. Нечто о русских в вагонах с сочувствием воспроизводит мнение корреспондента «Московских ведомостей» об уместности переселения татар из Крыма и подчеркивает опыт положительного влиянии прихода русских на Кавказ:

«Московские ведомости» выражают желание «не жалеть о татарах» и т. д. не для одной лишь политической стороны дела, не для одного лишь закрепления окраин, а выставляют и прямо экономическую потребность края. Они выставляют, как факт, что крымские татары даже доказали свою неспособность правильно возделывать почву Крыма и что русские, и именно южнорусы - на это гораздо будут способнее, и в доказательство указывают на Кавказ (Достоевский 1981: 54-55).

Достоевский при этом не уточняет, имеет ли он в виду приезд русских квалифицированных специалистов на Кавказ или же появление там русского населения. В любом случае, писатель транслирует колониальную установку: коренные народы находятся на более низком уровне развития цивилизации по сравнению с метрополией, и задача метрополии - «помочь» этим народам, вне зависимости от их собственного желания или согласия. Стоит, тем не менее, заметить, что речь идет о дальнейшем развитии края с учетом его природных особенностей. Не предполагается экспансия, ведущая к вывозу ресурсов и др.

Важным материалом для понимания места Кавказа в системе геополитических представлений Достоевского являются статьи, опубликованные им в Дневнике писателя в 1876-1878 годах. На эти годы выпали события Балканской войны, во время которой христианские славянские народы Балкан сражались за независимость от мусульманской Османской империи. Россия оказывала поддержку братьям-славянам, в русском обществе был большой патриотический подъем, и за военными действиями внимательно следил Достоевский. При этом один из фронтов войны пролегал на Кавказе, более того, современная официальная отечественная историография определяет в качестве одной из дат завершения Кавказской войны, в общей сложности длившейся едва ли не целый век, именно 1878 год, апеллируя к тому, что в этом году в последний раз на Кавказе применялась артиллерия. Поэтому активный интерес Достоевского к событиям и проблематике Балканской войны, обусловленной, главным образом, столкновением двух конфессий, мог быть распространен и на Кавказский фронт. Но пристальное внимание Достоевского не было обращено на Кавказ, парадок- 
сальным образом причина этого заключается в том, что в геополитической картине мира Достоевского Кавказ не является христианским регионом.

Об этом свидетельствует, например, статья Лакейство или деликатность?, опубликованная в Дневнике писателя за ноябрь 1877 года. Предпосылкой для ее написания стал Путевой дневник князя В.П. Мещерского, который отправился в Турцию через Кавказ и останавливался в Тифлисе. Заметка Мещерского Понедельник, 17 октября, в Тифлисе была опубликована 4 ноября в газете «Московские ведомости». В ней автор описывает пленных турок и рассуждает о российской «слабости»: Россия желает «рисоваться перед Европой». Этот сюжет обращает на себя внимание Достоевского, и он приводит в Дневнике писателя целый фрагмент заметки Мещерского:

Пленные паши выехали из Тифлиса. Их хотели везти на перекладных, но они взбунтовались и изволили объявить, что не поедут, ибо не привыкли к русским телегам. Вследствие этого им поданы были почтовые кареты и рессорные экипажи, с шестернями лошадей к каждому экипажу. На это они изволили заявить свое удовольствие, и, вследствие огромного числа забранных под них лошадей, бедные проезжающие по Военно-Грузинской дороге будут сидеть трое суток без лошадей. А офицеру русской службы, сопровождающему их, назначено 50 коп. суточных, и посадили его не в карету, а как сажают прислугу в омнибус! Все это гуманность! («Моск. ведом.» № 273) (Достоевский 1984: XXVI: 70).

Далее писатель рассуждает о том, что есть подлинная гуманность, а что есть «деликатность» в услугу европейского мнения, приводит наравне с тифлисским сюжетом и другие примеры подобного «либерального» отношения к врагам в угоду взглядам, устремленным на Россию со стороны Европы. В своих размышлениях Достоевский не прибегает к событиям сражений на Кавказском фронте, не затрагивает вопрос о потерях коренного населения Кавказа, о возмущении православных тифлиссцев в связи с почестями, оказанными русскими пленным туркам-мусульманам. Писатель откликается только на те события, которые соответствуют занимавшей его в то время проблематике: преклонению «либералов» перед Европой и - шире - взаимоотношениям Европы и России. Поглощенность Достоевского, как и русской интеллигенции в целом, этим вопросом, привела к тому, что кавказская проблематика им не улавливалась. К 1860-1870 годам военные, историки, путешественники уже подошли к вопросу осмысления Кавказа, но петербургская и московская интеллигенция еще не обращала на этот регион свое пристальное внимание, ее взгляд устремлен на Европу.

Вероятно, поэтому Достоевский полностью игнорирует важнейшую составляющую конфликта, лежащего в основе описанного Мещерским эпизода, которая вытекала из геополитического положения Кавказа: из его пограничного положения между христианским и мусульманским миром. Писатель не задается вопросом о существовании христианского Кавказа, находящегося на границе с мусульманским миром. На карте его геополитических представлений нет ни православной Армении, ни православной Грузии, которые на протяжении 
веков страдали от нападений мусульманской Османской империи также, как и балканские народы.

Достоевский, по сути дела, исключает Кавказ из ореола распространения православных народов. Так, например, в записных подготовительных тетрадях Достоевского к Дневнику писателя читаем:

Пишут, что мы охладели к Восточному вопросу. Это неправда: народ не охладел.... (...) Вот в постановке вопроса народностей и национальностей вопрос о Востоке, о восточных христианах слился в народном понятии не в одно человеколюбие и не в одну политическую задачу (...). Восточный вопрос - русский по преимуществу, национальный, народный и всегда популярный (Достоевский 1982: XXIV: 307).

При всей важности для Достоевского вопроса о восточных христианах, таковыми для писателя являются только славянские народы, в то время как положение южных христиан - кавказских народов - не проблематизируется. Получается, что славянское едва ли не стоит выше и важнее собственно христианского. Более того, Кавказ в сознании Достоевского оказывается гомогенным в своей символической причастности к мусульманскому миру.

В Дневнике писателя за 1876 год в главе Кифомокиевщина Достоевский пишет о России как христианской стране и размышляет о роли мусульманских народов (крымских, казанских татарах, сторонниках шариата на Кавказе) в ее составе, но опять-таки христианские народы Кавказа не упоминаются (Достоевский 1981: XXIII: 124-126). Более того, в главе В продолжение предыдущего Достоевский предполагает возникновение ситуации, при которой кавказские мусульманские народы могли бы взволноваться и пойти против христианской России, поддержав мусульманскую Турцию. Однако факт существования христианских кавказских народов, которые могли пострадать в таком случае от мусульман, он снова опускает:

Беспокойство, обнаружившееся в некоторых местностях Кавказа, (...) должно напомнить нам, что православный великорус живет в семье, что он не единственный, хотя и старший сын России (...). Чем виноват этот старший сын в семье, что мусульманин-кавказец, этот младший сын в семье, так восприимчив насчет своей веры и с такими понятиями, что, идя против турок, старший сын идет уже и против него и всего мусульманства?.. Вы тревожитесь, чтобы «старший брат в семье» (великорус) не оскорбил как-нибудь сердца младшего брата (татарина или кавказца) (Достоевский 1981: XXIII: 127).

И из этого фрагмента, и из приведенных выше цитат видно, что Достоевский понимает территорию Кавказа и населяющие ее народы как неотъемлемые составляющие в составе единой «братской» Российской империи, подчеркивает их кровную связь. И такая «братская» связь, в системе современных представлений, подразумевает равные права всех народов и конфессий. Но для Достоевского народы Кавказа - «младшие братья» великорусов, они находятся на вторых ролях в составе государства, это национальные и религиозные меньшинства, которые не могут претендовать на равные права с русскими. Кроме того, из проблематики снова выпадают православные народы Кавказа, они не упоминаются ни как братья по вере, ни даже как «младшие братья», они не существуют на геополитической карте Достоевского. 
Встает вопрос о том, почему христианские народы Кавказа остаются вне поля зрения Достоевского. С одной стороны, можно сделать вывод о том, что для писателя вопрос национальности оказывается едва ли не важнее вопроса вероисповедания. С другой стороны, находясь в рамках методологии постколониальных исследований, можно предположить, что Достоевскому были свойственны черты типично имперского, колонизаторского сознания. В его представлении периферия империи имела гомогенный характер и у отдельно взятого региона, который не был включен в какую-то другую проблематику, беспокоившую писателя, выделялась только ведущая характеристика. Для писателя не был характерен интерес к этнокультурным особенностям того или иного окраинного региона Российской империи, в его картине мира они не имели собственного символического капитала. Этнографический и антропологический интерес не был свойственен сознанию писателя, и его видение Кавказа является очередным тому подтверждением.

Третье объяснение может быть дано при условии выхода за пределы методологии постколониальных исследований и обращении к особенностям историофилософских воззрений Достоевского, а также специфике источников его знания о текущих событиях. Исследователями неоднократно приводились примеры, подтверждающие, что творческое сознание Достоевского чутко реагировало на опубликованную в газетах и журналах информацию, опубликованные статьи органично входили как в художественные, так и публицистические произведения писателя. При этом значима была ведущая проблема, которая больше всего занимала в тот или иной период Достоевского. В исследование этой проблемы он углублялся, и ее утверждение и обоснование было важнее, нежели всестороннее изучение ее противоречий и органичной сложности. Она служила своеобразным фильтром в отборе материала, на который реагировал писатель. Кавказская тема была на страницах печати конца 1870 годов, но тем не менее большее внимание уделялось балканским событиям, именно на них был сосредоточен общественный интерес. Для сознания Достоевского, поглощенного в то время славянским вопросом и взаимоотношениями мусульманского и христианского мира, было достаточно фактического знания об одном регионе. Для утверждения своей позиции по славянскому и христианскому вопросу писатель выбрал те сведения, которые лежали на поверхности. Внутренней потребности в поиске дополнительных примеров и аргументов, этнокультурных и геополитических параллелей, которые бы привели к появлению специального, углубленного интереса к Кавказу и его геополитическому положению, у Достоевского, поглощенного «русской идеей», не было.

\section{Библиография}

Alekseev, P.V. (2013). Musul'manskij vostok v poètike F.M. Dostoevskogo. Vestnik Omskogo universiteta, 4: 298-301 [Алексеев, П.В. (2013). Мусульманский восток в поэтике Ф.М. Достоевского. Вестник Омского университета, 4: 298-301]. 
Bagration-Muhraneli, I. L. (1994) Kavkaz kak utopiâ russkoj klassičeskoj literatury. Vestnik TGPU, 9: 83-88 [Багратион-Мухранели, И.Л. (1994). Кавказ как утопия русской классической литературы. Вестник ТГПУ, 9: 83-88].

Čhaidze, E. (2015). Politika i issledovanie russko-gruzinskih literaturnyh svâzej v Gruzii: s sovetskogo perioda po postsovetskij. Toronto Slavic Quartaly, 53: 92-112 [Чхаидзе, Е. (2015). Политика и исследование русско-грузинских литературных связей в Грузии: с советского периода по постсоветский. Toronto Slavic Quartaly, 53: 92-112].

Dostoevskij, F.M. (1972). Polnoe sobranie sočinenij: v 30 tomah. Leningrad: Nauka [Достоевский, Ф.М. (1972). Полное собрание сочинений: в 30 томах. Ленинград: Наука].

Dostoevskij, F.M. (1980). Polnoe sobranie sočinenij: v 30 tomah. Leningrad: Nauka [Достоевский, Ф.М. (1980). Полное собрание сочинений: в 30 томах. Ленинград: Наука].

Dostoevskij, F.M. (1981). Polnoe sobranie sočinenij. Leningrad: Nauka [Достоевский, Ф. М. (1981). Полное собрание сочинений: в 30 томах. Ленинград: Наука].

Dostoevskij, F.M. (1982). Polnoe sobranie sočinenij: v 30 tomah. Leningrad: Nauka [Достоевский Ф.М. (1982). Полное собрание сочинений: в 30 томах. Ленинград: Наука].

Dostoevskij, F.M. (1984a). Polnoe sobranie sočinenij: v 30 tomah. Leningrad: Nauka [Достоевский, Ф.М. (1984а). Полное собрание сочинений: в 30 томах. Ленинград: Наука].

Dostoevskij, F.M. (1984b). Polnoe sobranie sočinenij: v 30 tomah. Leningrad: Nauka [Достоевский, Ф.М. (1984b). Полное собрание сочинений: в 30 томах. Ленинград: Наука].

Dostoevskij, F.M. (1985). Polnoe sobranie sočinenij: v 30 tomah. Leningrad: Nauka [Достоевский, Ф. М. Полное собрание сочинений: в 30 томах. Ленинград: Наука].

Èjdel'man, N. (1990). Byt' možet za hrebtom Kavkaza (Russkâ̂ literatura i obŝestvennaâ mysl' pervoj poloviny XIX v. Kavkazskij kontekst). Moskva: Nauka [Эйдельман, Н. (1990). Быть может за хребтом Кавказа (Русская титература и общественная мысль первой половины ХІХ в. Кавказский контекст). Москва: Наука].

Ivanesko, A.E. (2018). Kavkazskie plenniki na imperskom frontire. Novoe prošloe, 3: 8-18 [Иванеско, А. Е. (2018). Кавказские пленники на имперском фронтире. Новое прошлое, 3: 8-18].

Kantor, V.K. (2010). «Sudit’ Bož û tvar'». Proročeskij pafos Dostoevskogo. Moskva: Rossijskaâ političeskaâ ènciklopediâ [Кантор, В.К. (2010). «Судить Божью тварь». Пророческий пафос Достоевского. Москва: Российская политическая энциклопедия].

Layton, S. (2005) Russian Literature and Empire: conquest of the Caucasus from Pushkin to Tolstoy. Cambridge: Cambridge University Press.

Lekke, M., Čhaidze, E. (2018). Rossiâ - Gruziâ posle imperii. V: Lekke M., Čheidze E. (Red.). Rossiâ-Gruziâ posle imperii: sbornik statej, Moskva: 31-55 [Лекке, М., Чхеидзе, Е. (2018). Россия Грузия после империи. В: Лекке, М., Чхаидзе, Е. (Ред.). Россия-Грузия после империи: сборник статей, Москва: 31-55].

Romanovskij, D. I. (1860). Kavkaz i Kavkazskâ̂ vojna. Publičnye lekcii, čitannye v zale Passaža general štaba polkovnikom Romanovskim D.I. Sankt-Petersburg [Романовский, Д. И. (1860). Кавказ и Кавказская война. Публичные лекции, читанные в зале Пассажа генерал итаба полковником Романовским Д.И. Санкт-Петербург].

Šaduri, V. (1948). Russkie pisateli o Gruzii. Tbilisi: Zarâ Vostoka [Шадури, В. (1948). Русские писатели о Грузии. Тбилиси: Заря Востока].

Ŝerbinin, A.I., Ŝerbinina N.G. (2018). Kartirovanie slavânskogo mira v «Dnevnike pisatelâ» F.M. Dostoevskogo. Rusin, 54 (4): 292-302 [Щербинин, А.И., Щербинина Н.Г. (2018). Картирование славянского мира в «Дневнике писателя» Ф. М. Достоевского. Русин, 54 (4): 292-302].

Sûjân, Mi. (2017). Kavkazskij motiv v «Zapiskah iz Mertvogo doma» F.M Dostoevskogo: skvoz' prizmu polemiki s M.Û. Lermontovym. Vestnik Rossijskogo universiteta družby narodov. Seriâ: Voprosy obrazovaniâ: âzyki i special'nost', 14 (4): 728-742 [Сюйян, Ми. (2017). Кавказ- 
ский мотив в «Записках из Мертвого дома» Ф.М. Достоевского: сквозь призму полемики с М. Ю. Лермонтовым. Вестник Российского университета дружбы народов. Серия: Вопросы образования: языки и специиальность, 14 (4): 728-742]. 